\title{
ПОВЫШЕНИЕ ФИНАНСОВОЙ УСТОЙЧИВОСТИ НЕФТЯНОЙ КОМПАНИИ В УСЛОВИЯХ НЕОПРЕДЕЛЕННОСТИ НА ПРИМЕРЕ АО «НК «КАЗМУНАЙГАЗ»
}

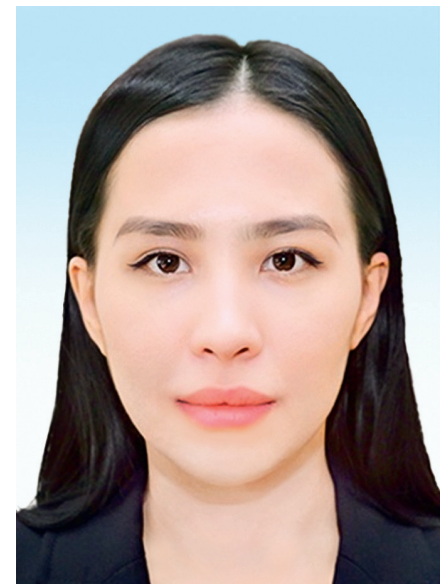

T.P. HA3APOBA, магистрант МВА Высшей школы бизнеса университета международного бизнеса, https://orcid.org/0000-00028634-989X

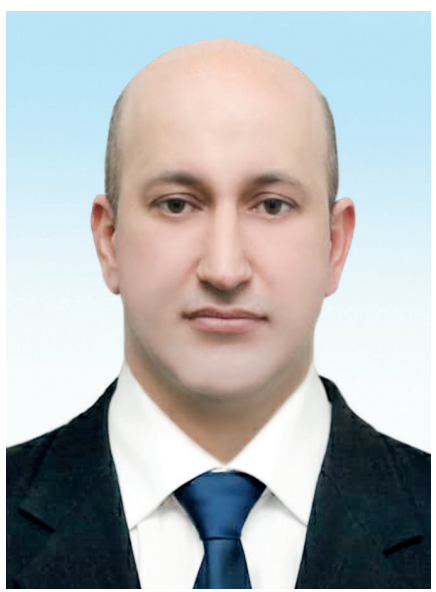

Ж.Д. ОСМАНОВ кандидат экономических наук, https://orcid.org/0000-00025225-0365

УНИВЕРСИТЕТ МЕЖДУНАРОДНОГО БИЗНЕСА,

Республика Казахстан, 050010, г. Алматы, пр. Абая, 8А

Деятельность нефтяных компаний во всем мире подвержена влиянию внешних фракторов, некоторым из которых свойственна неопределенность. Управление фринансовой устойчивостью компании в условиях неопределенности приобретает главное значение в поддержании ее платежеспособности, ликвидности и конкурентоспособности.

На основании опубликованных данных консолидированной фринансовой отчетности проведен вертикальный и трендовый анализы финансовых показателей компании АО «НК «КазМунайГаз» за 2018-2020 г2., с последующим анализом коэфрфрициентов ее фринансовой устойчивости. По результатам анализа, был определен тип финансовой устойчивости присущий компании в анализируемом периоде. Далее, в соответствии с данными, полученными в ходе анализа, были сделаны выводы и предложена рекомендация по повышению фринансовой устойчивости компании.

КЛЮЧЕВЫЕ СЛОВА: фринансовый менеджмент, фринансовый анализ, фринансовая устойчивость, дебиторская задолженность, нефтегазовая отрасль.

\footnotetext{
* Адрес для переписки. E-mail: zhasym@mail.ru
} 


\title{
"ҚАЗМҰНАЙГАЗ "ҰК" АҚ МЫСАЛЫНДА БЕЛГІСІЗДІК ЖАҒДАЙЫНДА МҰНАЙ КОМПАНИЯСЫНЫН ҚАРЖЫЛЫҚ ТҰРАҚТЫЛЫҒЫН АРТТЫРУ
}

T.P. НАЗАРОВА, Халықаралық Бизнес Университеті Жоғары бизнес мектебінің МВА магистранты, https://orcid.org/0000-0002-8634-989X

Ж.Д. ОСмАНОВ*, Халықаралық Бизнес Университетінің экономика ғылымдарының кандидаты, https://orcid.org/0000-0002-5225-0365

\author{
ХАЛЫҚАРАЛЫҚ БИЗНЕС УНИВЕРСИТЕТІ, \\ Қазақстан Республикасы,050010, Алматы қаласы, Абай даңғылы, 8А
}

Бүкіл әлемде мұнай компанияларының қызметі сыртқы фракторлардың әсеріне ұшырайды, олардың кейбіреулері белгісіздікпен сипатталады. Компанияның қаржылық тұрақтылығын белгісіздік жағдайында басқару оның төлем қабілеттілігін, өтімділігін және бәсекеге қабілеттілігін сақтау үшін маңызды болып табылады.

Шоғырландырылған қаржылық есептіліктің жарияланған деректері негізінде "ҚазМұнайГаз" Ұлттық компаниясы" АҚ компаниясының 2018-2020 жылдардағы қаржылық көрсеткіштеріне сатылас және трендтік талдау жүргізіліп, кейіннен оның қаржылық тұрақтылықкоэфффициенттерін талдау жүргізілді. Талдау нәтижелері бойынша талдау кезеңінде компанияға тән қаржылық тұрақтылықтың түрі анықталды. Бұдан әрі, талдау барысында алынған деректерге сәйкес, қорытындылар жасалды және компанияның қаржылық тұрақтылығын арттыру бойынша ұсыныс беріледі.

ТҮЙıн сөзДЕР: қаржылық менеджмент, қаржылық талдау, қаржылық тұрақтылық, дебиторлық берешек, мұнай-газ саласы.

\section{IMPROVEMENT OF THE FINANCIAL SUSTAINABILITY OF OIL COMPANY IN CODNDITIONS OF UNCERTAINTY ON THE EXAMPLE OF NC KAZMUNAYGAS JSC}

T.R. NAZAROVA, MBA student at GSB, University of International Business, https://orcid.org/00000002-8634-989X

Z.D. OSMANOV*, Candidate of Sciences in Economics, University of International Business, https:// orcid.org/0000-0002-5225-0365

UNIVERSITY OF INTERNATIONAL BUSINESS

8A, Abay ave. Almaty, 050010, Republic of Kazakhstan

The activities of world oil companies are subject to the influence of external factors, some of which are characterized by uncertainty. Managing the financial sustainability of a company under conditions of uncertainty becomes of the main importance in maintaining its solvency, liquidity, and competitiveness.

Based on the published data of the consolidated financial statements, vertical and trend analyses of the financial performance indicators of NC KazMunayGas JSC for 2018-2020 were carried out, followed by an analysis of its financial sustainability coefficients. According to the results of the analysis there was determined the type of financial sustainability inherent in the company in the analyzed period. Further, based on the results of the analysis, we made the conclusions and proposed recommendations to improve the financial sustainability of the Company.

KEY WORDS: financial management, financial analysis, financial sustainability, accounts receivable, oil and gas industry. 
еятельность нефтяных компаний во всем мире подвержена влиянию внешних факторов, некоторым из которых свойственна неопределенность. Рынку нефти свойственна волатильность цен, что доказывается при ретроспективном анализе динамики изменения мировой цены на нефть. Среди основных факторов, влияющих на колебания цен на нефть, можно выделить геополитические, экономические и технические факторы. В 2020 году на дополнительное негативное влияние на волатильность цен на нефть оказало распространение коронавирусной инфекции COVID-19. Пандемия коронавируса и меры удержания, связанные с ней, вызвали беспрецедентное снижение экономической активности и обвал спроса на мировом рынке нефти [1, с. 16], что в свою очередь оказало негативные изменения на выполнение финансовых показателей рядом нефтяных компаний, среди которых не исключением являются и казахстанские компании. Несомненно, чтобы преодолеть все вышеперечисленные трудности и вызовы нефтегазовые компании нуждаются в своевременном проведении финансового анализа, и в частности, ревизии своей финансовой устойчивости. Так как отсутствие баланса между собственным и заемным капиталом в условиях нестабильной внешней среды подвергает компанию большому риску, и при недостаточности запасов такая компания имеет риск не расплатиться по своим обязательствам, что в конечном итоге может привести к банкротству [2, с. 23].

Комплексный анализ финансового состояния состоит из анализа динамики и структуры активов и источников их формирования, анализа по абсолютным данным бухгалтерского баланса, а также анализа коэффициентов финансовой устойчивости, ликвидности и платежеспособности, рентабельности [3, с. 329].

Финансовая устойчивость представляет собой один из важнейших показателей экономической безопасности компании в условиях рыночной экономики [4, с. 39].

По мнению И. Ю. Евстафьевой и В. А. Черненко, анализ финансовой устойчивости проводится для определения степени независимости предприятия от внешних источников финансирования и способности исполнения своих долгосрочных обязательств [5, с. 85]. При этом, В. П. Литовченко считает, что финансовая устойчивость в решающей мере зависит от степени обеспеченности предприятия собственными оборотными средствами [6, с. 60].

Анализ финансовой устойчивости основан на расчете абсолютных и относительных показателей [7, с. 63]. При расчете абсолютных показателей финансовой устойчивости используются показатели, характеризующие степень обеспеченности запасов источниками их формирования [8, с. 36]. В зависимости от степени обеспеченности запасов источниками их формирования выделяют четыре типа финансовой устойчивости: абсолютная финансовая устойчивость, нормальная финансовая устойчивость, относительная финансовая устойчивость и абсолютная финансовая неустойчивость [8, с. 37].

Расчет относительных показателей (коэффициентов финансовой устойчивости) основан на соотношениях и зависимостях между статьями бухгалтерского баланса. При анализе относительных показателей финансовой устойчивости исследуется 
их динамика и уровень в сравнении с нормативными значениями [7, с. 65]. Чем лучше коэффициентные показатели финансовой устойчивости, тем ниже уровень финансового риска (при прочих равных условиях), с которым данное предприятие ассоциируется у внешних контрагентов [8, с. 87].

\section{Методы исследования}

Вертикальный анализ, трендовый анализ, метод группировки и сравнения, анализ коэффициентов.

\section{Гипотеза}

Обладает ли нефтегазовая компания АО «НК «КазМунайГаз» финансовой устойчивостью?

\section{Описание базы для сбора данных}

Базой для сбора данных являются платформа научных публикаций Google Scholar, учебные пособия, а также финансовые отчеты компании.

Объектом исследования выступит нефтегазовая компания - АО НК «КазМунайГаз». По данным финансовой отчетности Компании проведем расчет показателей финансовой устойчивости.

$\mathrm{AO}$ «НК «КазМунайГаз» (далее КМГ) является ведущей вертикально - интегрированной нефтегазовой компанией Казахстана. КМГ управляет активами по всему производственному циклу - от разведки и добычи углеводородов до транспортировки, переработки и предоставления сервисных услуг» [9].

Согласно Стратегии КМГ до 2025 года, основными целями являются:

- повышение уровня запасов и объемов добычи;

- укрепление финансовой устойчивости и создание стоимости;

- гарантия возвратности инвестиций.

В рамках установленных стратегических целей компания предпринимает определенные меры для реализации стратегии по основным направлениям производственного цикла.

Для анализа финансовой устойчивости Компании воспользуемся консолидированной финансовой отчетностью АО «НК «КазМунайГаз» за 2018-2020 гг, составленной в соответствии с Международными стандартами финансовой отчетности (МСФО).

Рассмотрим структуры активов в таблице 1 .

Долгосрочные (внеоборотные) активы в структуре баланса активов занимают значительную долю, при этом за анализируемый период 2018-2020 гг. наблюдается рост этих активов с 76,69\% до 83,10\%. Стоит отметить, что инвестиции в совместные предприятия и основные средства являются главными статьями внеоборотных активов компании. В 2020 году их доли в структуре долгосрочных активов составили $44,16 \%$ и $29,82 \%$ соответственно. Также нужно обратить внимание на то, что статья «займы и дебиторская задолженность от связанных сторон» в структуре внеоборотных активов занимает третье место по долевому объему $(4,67 \%)$.

В 2020 году на текущие (оборотные) активы в структуре баланса активов приходится доля в $16,58 \%$. Следует отметить, что их доля в общей структуре активов с каждым годом снижается, за 2018-2020 гг. снижение составило 6,29\%. Большую 
Таблица 1 - Сокращенная структура активов

АО «НК «КазМунайГаз» за 2018-2020 гг.

\begin{tabular}{|c|c|c|c|c|c|c|}
\hline \multirow{2}{*}{$\begin{array}{c}\text { Наименование } \\
\text { статей }\end{array}$} & \multicolumn{3}{|c|}{$\begin{array}{c}\text { Абсолютные величины, } \\
\text { млн тенге }\end{array}$} & \multicolumn{3}{|c|}{ Удельный вес, \% } \\
\hline & 2018 г. & 2019 г. & 2020 г. & 2018 г. & 2019 г. & 2020 г. \\
\hline \multicolumn{7}{|l|}{$\begin{array}{c}\text { 1. Долгосрочные } \\
\text { активы }\end{array}$} \\
\hline Основные средства & 4515170 & 4484271 & 4369745 & 2,22 & 31,84 & 29,82 \\
\hline $\begin{array}{c}\text { Инвестиции } \\
\text { в совместные } \\
\text { предприятия и } \\
\text { ассоциированные } \\
\text { компании }\end{array}$ & 4895444 & 5590384 & 6471021 & 34,93 & 39,70 & 44,16 \\
\hline $\begin{array}{c}\text { Займы и дебиторская } \\
\text { задолженность от } \\
\text { связанных сторон }\end{array}$ & 638528 & 615546 & 684610 & 4,56 & 4,37 & 4,67 \\
\hline $\begin{array}{c}\text { Итого долгосрочных } \\
\text { активов }\end{array}$ & 10748329 & 11442004 & 12176864 & 76,69 & 81,25 & 83,10 \\
\hline \multicolumn{7}{|l|}{ 2. Текущие активы } \\
\hline $\begin{array}{c}\text { Товарно- } \\
\text { материальные } \\
\text { запасы }\end{array}$ & 312299 & 281215 & 228065 & 2,23 & 2,00 & 1,56 \\
\hline $\begin{array}{c}\text { Торговая } \\
\text { дебиторская } \\
\text { задолженность }\end{array}$ & 493977 & 397757 & 422821 & 3,52 & 2,82 & 2,89 \\
\hline $\begin{array}{c}\text { Краткосрочные } \\
\text { банковские вклады }\end{array}$ & 386459 & 359504 & 282472 & 2,76 & 2,55 & 1,93 \\
\hline $\begin{array}{c}\text { Денежные средства и } \\
\text { их эквиваленты }\end{array}$ & 1539453 & 1064452 & 1145864 & 10,98 & 7,56 & 7,82 \\
\hline $\begin{array}{c}\text { Итого текущих } \\
\text { активов }\end{array}$ & 3205191 & 2632307 & 2429905 & 22,87 & 18,69 & 16,58 \\
\hline Итого активов & 14015280 & 14081915 & 14653287 & 100 & 100 & 100 \\
\hline
\end{tabular}

Примечание: таблица 1 составлена на основе данных консолидированной финансовой отчетности КМГ. Удельный вес показателей рассчитан авторами.

долю в структуре оборотных активов в 2020 году занимали денежные средства и их эквиваленты (7,82\%), и торговая дебиторская задолженность (2,89\%).

Далее, проанализируем структуру пассивов Компании в таблице 2. 
Таблица 2 - Сокращенная структура пассивов

АО «НК «КазМунайГаз» за 2018-2020 гг.

\begin{tabular}{|c|c|c|c|c|c|c|}
\hline \multirow{2}{*}{ Наименование статей } & \multicolumn{3}{|c|}{$\begin{array}{c}\text { Абсолютные величины, } \\
\text { млн. тенге }\end{array}$} & \multicolumn{3}{|c|}{ Удельный вес, \% } \\
\hline & 2018 r. & 2019 г. & 2020 г. & 2018 r. & 2019 г. & 2020 r. \\
\hline \multicolumn{7}{|l|}{ Капитал } \\
\hline Уставный капитал & 916541 & 916541 & 916541 & 6,54 & 6,51 & 6,25 \\
\hline $\begin{array}{l}\text { Резерв от пересчета } \\
\text { валюты отчетности }\end{array}$ & 1764108 & 1731747 & 2146035 & 12,6 & 12,3 & 14,65 \\
\hline $\begin{array}{c}\text { Нераспределенная } \\
\text { прибыль }\end{array}$ & 4341063 & 5469236 & 5636705 & 30,97 & 38,8 & 38,47 \\
\hline $\begin{array}{c}\text { Относящийся } \\
\text { к акционерам } \\
\text { Материнской компании }\end{array}$ & 7062589 & 8158401 & 8708320 & 50,39 & 57,9 & 59,43 \\
\hline Итого капитала & 7143069 & 8196656 & 8636679 & 50,97 & 58,2 & 58,94 \\
\hline \multicolumn{7}{|l|}{$\begin{array}{l}\text { Долгосрочные } \\
\text { обязательства }\end{array}$} \\
\hline Займы & 3822648 & 3584076 & 3716892 & 27,27 & 25,4 & 25,37 \\
\hline $\begin{array}{c}\text { Обязательства по } \\
\text { отсроченному налогу }\end{array}$ & 479598 & 509462 & 555894 & 3,42 & 3,62 & 3,79 \\
\hline $\begin{array}{c}\text { Итого долгосрочных } \\
\text { обязательств }\end{array}$ & 5064056 & 4446817 & 4683233 & 36,13 & 31,6 & 31,96 \\
\hline \multicolumn{7}{|l|}{ Текущие обязательства } \\
\hline Займы & 330590 & 253428 & 361556 & 2,36 & 1,80 & 2,47 \\
\hline $\begin{array}{c}\text { Торговая кредиторская } \\
\text { задолженность }\end{array}$ & 632739 & 667861 & 536922 & 4,51 & 4,74 & 3,66 \\
\hline $\begin{array}{c}\text { Итого текущих } \\
\text { обязательств }\end{array}$ & 1803116 & 1438442 & 1333375 & 12,87 & 10,2 & 9,10 \\
\hline $\begin{array}{c}\text { Итого капитала и } \\
\text { обязательств }\end{array}$ & 14015280 & 14081915 & 14653287 & 100 & 100 & 100 \\
\hline
\end{tabular}

Примечание: таблица 2 составлена на основе данных консолидированной финансовой отчетности КМГ. Удельный вес показателей рассчитан авторами.

Мы видим, что собственный капитал в структуре пассивов занимает большую долю и имеет тенденцию к росту. За анализируемый период с 2018 по 2020 гг. собственный капитал вырос с 50,97\% до 58,94\%. При этом основной рост приходится за счет нераспределенной прибыли (в 2020 г. $+38,47 \%$ ). 
Общая доля долгосрочных обязательств в структуре пассивов в 2020 году составила $31,96 \%$, за последние три года наблюдается снижение на 4,17\%. Снижение в основном обеспечено за счет окончания выполнения обязательств в рамках предоплаты по договору поставки нефти в 2018 году. Однако в структуре долгосрочных обязательств значительную долю все же занимает статья «займы». При этом, с 2018 по 2019 год наблюдалось снижение на -6,2\%, но с 2019 по 2020 год вновь наблюдается рост заемных средств на $+3,7 \%$.

В 2020 году текущие (краткосрочные) обязательства в структуре пассивов занимали 9,10\% (-3,77\% с 2018 года). Аналогично долгосрочным обязательствам наблюдается снижение за счет покрытия обязательств в рамках предоплаты по договору поставок нефти. Главными статьями краткосрочных обязательств выступают торговая кредиторская задолженность и займы. Их доли в структуре составляют $3,66 \%$ и $2,47 \%$ соответственно.

Теперь, используя исходные данные бухгалтерского баланса, произведем расчет абсолютных показателей финансовой устойчивости (таблица 3) для анализа степени обеспеченности деятельности компании источниками финансирования. В частности, через расчет трехкомпонентного показателя финансовой устойчивости можно получить информацию об обеспечении источниками финансирования запасов и затрат.

Таблица 3 - Трехкомпонентный показатель финансовой устойчивости АО «НК «КазМунайГаз» за 2018-2020 гг.

\begin{tabular}{|c|c|c|c|c|}
\hline \multirow[t]{2}{*}{ Наименование показателей } & \multicolumn{3}{|c|}{$\begin{array}{l}\text { Значение показателя } \\
\text { (млн тенге) }\end{array}$} & \multirow{2}{*}{$\begin{array}{c}\text { Абсолютные } \\
\text { изменения } \\
\text { (млн. тенге) }\end{array}$} \\
\hline & 2018 г. & 2019 г. & 2020 г. & \\
\hline $\begin{array}{c}\text { Наличие собственных оборотных } \\
\text { средств (СОС) }\end{array}$ & 1458796 & 1201469 & 1143048 & -315748 \\
\hline $\begin{array}{c}\text { Наличие собственных и долгосрочных } \\
\text { источников финансирования запасов (СДИ) }\end{array}$ & 6522852 & 5648286 & 5826281 & -696571 \\
\hline $\begin{array}{c}\text { Общая величина основных источников } \\
\text { формирования запасов (ОИЗ) }\end{array}$ & 8331007 & 7086728 & 7159656 & -1171351 \\
\hline $\begin{array}{c}\text { Излишек(+), недостаток(-) собственных } \\
\text { оборотных средств }(\triangle C O C)\end{array}$ & 1146497 & 920254 & 914983 & -231514 \\
\hline $\begin{array}{c}\text { Излишек(+), недостаток(-) собственных } \\
\text { и долгосрочных источников } \\
\text { финансирования запасов ( } \triangle \text { СДИ) }\end{array}$ & 6210553 & 5367071 & 5598216 & -612337 \\
\hline $\begin{array}{c}\text { Излишек(+), недостаток(-) общей } \\
\text { величины основных источников } \\
\text { покрытия запасов ( } \triangle \text { ОИЗ) }\end{array}$ & 8018708 & 6805513 & 6931591 & -1087117 \\
\hline $\begin{array}{c}\text { Трехкомпонентный показатель } \\
\text { финансовой устойчивости }\end{array}$ & $(1,1,1)$ & $(1,1,1)$ & $(1,1,1)$ & \\
\hline
\end{tabular}

Примечание: таблица 3 составлена на основе данных консолидированной финансовой отчетности КМГ. Расчет по указанным формулам произведен авторами. 
Проделанный расчет показывает, что в период с 2018 по 2020 гг. Компания имела абсолютную финансовую устойчивость. Это означает, что у КМГ было достаточно собственных оборотных средства для покрытия запасов и затрат. Но, следует отметить, что за анализируемый период в динамике наблюдается снижение показателей наличия как собственного оборотного (рабочего) капитала, так и долгосрочных и краткосрочных источников заемного финансирования.

Далее, рассчитаем относительные показатели финансовой устойчивости $\mathrm{AO}$ «НК «КазМунайГаз» (таблища 4).

Таблица 4 - Относительные показатели финансовой устойчивости АО «НК «КазМунайГаз» за 2018-2020 гг.

\begin{tabular}{|c|c|c|c|c|c|}
\hline \multirow{2}{*}{ Показатель } & \multirow{2}{*}{$\begin{array}{l}\text { Формула } \\
\text { расчета }\end{array}$} & \multicolumn{3}{|c|}{ Значения по годам } & \multirow{2}{*}{$\begin{array}{l}\text { Оптимальное } \\
\text { значение }\end{array}$} \\
\hline & & 2018 & 2019 & 2020 & \\
\hline Коэффициент автономии & CK/B6 & 0,51 & 0,58 & 0,59 & $\geq 0,5$ \\
\hline $\begin{array}{c}\text { Коэффициент соотношения } \\
\text { заемных и собственных } \\
\text { средств (финансового рычага) }\end{array}$ & $\begin{array}{c}(\mathrm{ДO}+\mathrm{КО}) / \\
\text { СК }\end{array}$ & 0,96 & 0,72 & 0,70 & $\leq 1$ \\
\hline $\begin{array}{c}\text { Коэффициент } \\
\text { соотношения мобильных и } \\
\text { иммобилизованных средств }\end{array}$ & $\mathrm{OA} / \mathrm{BOA}$ & 0,30 & 0,23 & 0,20 & - \\
\hline $\begin{array}{c}\text { Коэффициент маневренности } \\
\text { собственного капитала }\end{array}$ & $\mathrm{COC} / \mathrm{CK}$ & 0,20 & 0,15 & 0,13 & - \\
\hline $\begin{array}{c}\text { Коэффициент обеспеченности } \\
\text { собственными оборотными } \\
\text { средствами (СОС) }\end{array}$ & COC/OA & 0,45 & 0,46 & 0,46 & $\geq 0,1$ \\
\hline $\begin{array}{l}\text { Коэффициент долгосрочного } \\
\text { привлечения заемных средств }\end{array}$ & $\begin{array}{c}\text { ДО/ } \\
\text { (ДО+СК) }\end{array}$ & 0,41 & 0,35 & 0,35 & - \\
\hline
\end{tabular}

Примечание: таблица 4 составлена на основе данных консолидированной финансовой отчетности КМГ. Расчет по указанным формулам произведен авторами.

Из полученного расчета можно сделать вывод о том, что коэффициент автономии в анализируемый период показывает рост в динамике и соответствует рамкам оптимального значения. Это означает, что компания может покрыть все обязательства ее собственными средствами. Рост данного коэффициента говорит о снижении риска финансовых затруднений в будущем и укреплении финансовой независимости компании [3, с. 299].

Коэффициент финансового рычага за анализируемый период показывает снижение с 0,92 до 0,7 . Это означает, что у компании снижается зависимость от заемных средств, что способствует повышению благосостояния акционеров компании, 
так как высокая доля долга в структуре капитала компаний, наоборот, приводит к постоянному снижению благосостояния акционеров [10, с. 4178].

Коэффициент соотношения мобильных и иммобилизованных средств в динамике показывает, что Компания больше вкладывается в наращивание внеоборотных активов.

Коэффициент маневренности собственного капитала показывает нисходящий тренд. За последние три года, с 2018 по 2020 гг., значение данного показателя снизилось с 0,20 до 0,13. Это означает, что снижается мобильность собственных средства компании.

Коэффициент обеспеченности собственными оборотными средствами незначительно повысился за три года до уровня 0,46 , при рекомендуемом значении $>0,1$, можно считать, что обеспеченность собственными оборотными средствами в норме.

Коэффициент финансовой устойчивости в целом за анализируемый период показывает рост и соответствует нормативному значению. Тем самым указывает на то, что доля долговременных источников финансирования намного выше, чем краткосрочных.

Коэффициент долгосрочного привлечения заемных средств в динамике демонстрирует снижение, что говорит о снижении зависимости деятельности Компании от долговременных источников заемных средств.

\section{Выводы}

В результате проведенного анализа консолидированной финансовой отчетности $\mathrm{AO}$ «НК «КазМунайГаз» можно сделать вывод, что Компания в анализируемый период с 2018 по 2020 года обладала абсолютной финансовой устойчивостью. Это означает, что Компания характеризуется тем, что все запасы предприятия покрываются собственными оборотными средствами. Также наблюдается снижение зависимости от внешних источников финансирования и повышение объема собственного капитала. Но, следует отметить, что данные, полученные в ходе анализа, показали, что в компании наблюдается тренд роста займов и дебиторской задолженности в структуре внеоборотных активов и торговой дебиторской задолженности в структуре оборотных активов. Это, в свою очередь, может повлиять на снижение ликвидности или повышения использования заемных средств, что, в конечном итоге, может повлиять на финансовую устойчивость компании. В этой связи, можно предложить обратить внимание на управление дебиторской задолженностью.

\section{ЛИТЕРАТУРА}

1 Зайцева О.П., Герасименко О.А. Влияние коронавируса на нефтяной рынок // Электронный научно-методический журнал Омского ГАУ. - 2020. - №4(23) октябрь-декабрь. - С. 16. [Zayceva O. P., Gerasimenko O. A. Vliyanie koronavirusa na neftyanoy rynok// Elektronniy nauchno-metodicheskiy zhurnal Omskogo GAU. - 2020. - No.4(23) oktyabr'-noyabr'. - S.16].

2 Юшаков А.С. Проблемы повышения фринансовой устойчивости организаций в современных условиях // Стратегии бизнеса. - 2017. - №8(40). - С. 22-24. [Yushakov A.S. Problemy povysheniya finansovoy ustoychivosti organizaciy v sovremennyh usloviyah // Strategii biznesa. - 2017. - No.8(40). - S.22-24]. 
3 Шеремет А.Д. Анализ и диагностика финансово-хозяйственной деятельности предприятия. - М.: ИНФРА-М, 2017. - 374 с. [Sheremet A.D. Analiz i diagnostika finansovohozyaystvennoy deyatel'nosti predpriyatiya. - Moskva: INFRA-M, 2017. - S. 374].

4 Кругляк Л.И., Асташкин Д. Ю. Финансовая устойчивость как фактор экономической безопасности ПАО «Лукойл» // Материалы Всероссийской научно-практической конференции «Национальная безопасность России: актуальные аспекты». - Санкт-Петербург, Россия. - Март 2018. - C. 39-45. [Kruglyak L.I., AstashkinD. Yu. Finansovaya ustoychivost' kak factor ekonomicheskoy bezopasnosti PAO «Lukoyl» // Materialy Vserossiyskoy nauchno-prakticheskoy konferencii «Nacional'naya bezopasnost' Rossii: aktual'nye aspekty». - Sankt-Peterburg, Rossiya. - Mart 2018. - S. 39-45].

5 Евстафьева И. Ю., Черненко В. А. Финансовый анализ: учебник и практикум для бакалавриата и магистратуры. - М.: Издательство Юрайт, 2016. - 336 c. [Evstaf'eval. Yu., ChernenkoV. A. Finansoviy analiz: uchebnik i praktikum dlya bakalavriata i magistratury. - Moskva: Publ. Yurayt, 2016. - S. 336].

6 Литовченко В.П. Финансовый анализ: учебное пособие. - М.: Издательско-торговая корпорация «Дашков и К», 2018. - 214 с. [LitovchenkoV. P. Finansoviyanaliz: uchebnoeposobie.- Moskva: Publ. «DashkoviK», 2018. - S. 214].

7 Базиль Т.В. Анализ финансовой отчетности коммерческих организаций: учебное пособие. - Южно-Сахалинск: СахГУ, 2020. - 148 с. [Bazil' T.V. Analiz finansovoy otchetnosti kommercheskih organizaciy: uchebnoe posobie. - Yuzhno-Sakhalinsk: SakhGU, 2020. - S. 148].

8 Крылов С. И. Финансовый анализ. - Екатеринбург: Издательство Уральского университета, 2016. - 160 с. [Krylov S. I. Finansoviy analiz. - Yekaterinburg: Publ. Ural'skiyuniversitet, 2016. - S.160].

9 Офрициальный сайт АО «НК «КазМунайГаз» =Oficial'niy sayt AO NK «KazMunajGaz» Access mode: https://www.kmg.kz/rus/kompaniya/obshaya_informaciya/ (Accessed: 10.08.2021).

10 Ahmadu Abubakar. Financial leverage and financial performance of oil and gas companies in Nigeria: A re-examination // Turkish journal of computer and mathematics education. - 2021. - Vol. 12 No.3(2021). - C. 4170-4180. 